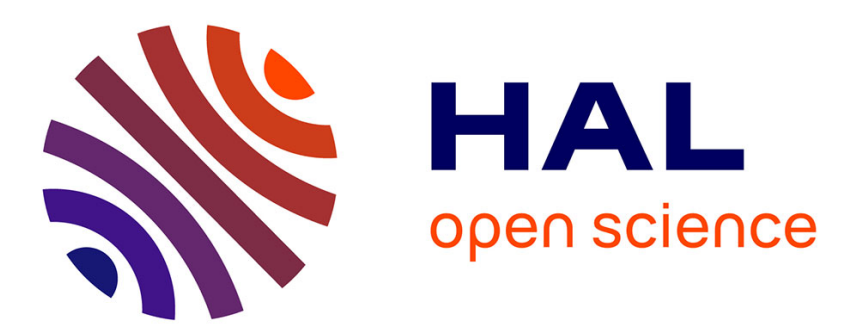

\title{
Interface structure and defects in directionally solidified oxide-oxide eutectic composites
}

\author{
Sylvie Lartigue-Korinek, Laura Londaitzbéhère, Leo Mazerolles
}

\section{To cite this version:}

Sylvie Lartigue-Korinek, Laura Londaitzbéhère, Leo Mazerolles. Interface structure and defects in directionally solidified oxide-oxide eutectic composites. Journal of Materials Science, 2020, 10.1007/s10853-020-04389-w . hal-03009750

\section{HAL Id: hal-03009750 \\ https://hal.science/hal-03009750}

Submitted on 30 Nov 2020

HAL is a multi-disciplinary open access archive for the deposit and dissemination of scientific research documents, whether they are published or not. The documents may come from teaching and research institutions in France or abroad, or from public or private research centers.
L'archive ouverte pluridisciplinaire HAL, est destinée au dépôt et à la diffusion de documents scientifiques de niveau recherche, publiés ou non, émanant des établissements d'enseignement et de recherche français ou étrangers, des laboratoires publics ou privés. 


\section{Interface structure and defects in directionally solidified oxide-oxide eutectic composites}

Sylvie Lartigue-Korinek ${ }^{*}$

* Corresponding author

Institut de Chimie et des Matériaux Paris-Est , UMR 7182 CNRS-Université Paris Est, 2-8

rue H. Dunant, 94320 -Thiais, France. Phone number 33156703031

sylvie.lartigue@icmpe.cnrs.fr

Laura Londaitzbéhère

Institut de Chimie et des Matériaux Paris-Est, UMR 7182 CNRS-Université Paris Est, 2-8

rue H. Dunant, 94320 -Thiais, France.

londaitzbehere@icmpe.cnrs.fr

Leo Mazerolles

Institut de Chimie et des Matériaux Paris-Est , UMR 7182 CNRS-Université Paris Est, 2-8 rue H. Dunant, 94320 -Thiais, France.

mazerolles@icmpe.cnrs.fr 


\title{
Interface structure and defects in directionally solidified oxide-oxide eutectic composites
}

\author{
Sylvie Lartigue-Korinek ${ }^{*}$, Laura Londaitzbéhère, Leo Mazerolles
}

Institut de Chimie et des Matériaux Paris-Est, UMR 7182 CNRS-Université Paris Est, 2-8 rue H. Dunant, 94320 -Thiais, France.

* Corresponding author

\begin{abstract}
Interfaces in ternary oxide-oxide eutectic composites prepared by directional solidification are investigated at the atomic scale. Two systems are studied that both display a chinese script interconnected microstructure, associating three monocrystalline phases, alumina (A), yttrium aluminium garnet $(\mathrm{Y})$ phase or a perovskite phase $\mathrm{SmAlO}_{3}(\mathrm{~S})$, and zirconia (Z), i.e. $\mathrm{Al}_{2} \mathrm{O}_{3^{-}}$ $\mathrm{Y}_{3} \mathrm{Al}_{5} \mathrm{O}_{12}-\mathrm{ZrO}_{2}(\mathrm{~A}-\mathrm{Y}-\mathrm{Z})$ or $\mathrm{Al}_{2} \mathrm{O}_{3}-\mathrm{SmAlO}_{3}-\mathrm{ZrO}_{2}(\mathrm{~A}-\mathrm{S}-\mathrm{Z})$.

Most interfaces are semicoherent. The curved interfaces between $\mathrm{A}$ and $\mathrm{Z}$ nodules are strongly faceted and parallel to dense planes of both crystals or to dense planes of alumina. The same features occur for A-S interfaces, which show longer facets. The steps between facets accommodate the misfits. Y-A and Y-Z interfaces are often parallel to a dense plane of one crystal owing to a slight deviation of the $\mathrm{Y}$ phase from the perfect orientation relationship (OR). The OR between $\mathrm{Y}$ and A phases found in binary eutectic is modified by the presence of Z. Similarly, although the same OR occurs between A and Z in binary and ternary eutectics with the $\mathrm{Y}$ phase, this OR is modified by the presence of $\mathrm{S}$. The discussion emphasizes the predominant role of interfacial order on the final orientation relationships.
\end{abstract}

Keywords: oxide/oxide eutectics, interfaces, atomic scale, transmission electron microscopy 


\section{Introduction}

Structural oxide-oxide materials in the systems $\mathrm{Al}_{2} \mathrm{O}_{3}-\mathrm{RE}_{2} \mathrm{O}_{3}$ (Called A-Y if RE: Y or A-E if RE: Er) prepared at eutectic composition by directional solidification from the melt display an interconnected microstructure of two entangled monocrystalline phases forming a three dimensional and continuous network [1-3]. They show outstanding mechanical properties up to the melting temperature of the order of $1700^{\circ} \mathrm{C}$ with a stable microstructure [1-9]. A-Y and similar systems are promising for gas turbines in place of $\mathrm{Ni}$ based superalloys whose working temperature does not exceed $1150^{\circ} \mathrm{C}$. However they have a limited fracture toughness of about 2-2.5 MPa.m ${ }^{1 / 2}$ at ambient temperature $[4,6,10]$. This limitation is overcome by ternary addition of $\mathrm{Z}$, which introduces thermo-elastic residual stresses, reduces domain size and makes interfaces more rounded and more finely faceted than in the case of A-Y [11-15]. Toughness values in the range 4-5 MPa.m ${ }^{1 / 2}$ were measured [7, 11-13].

Binary or ternary eutectic composites prepared with alumina and a perovskite phase, either $\mathrm{GdAlO}_{3}[5,7,16,17]$ or, more recently, $\mathrm{SmAlO}_{3}[18,19]$ display a similar microstructure. The $\mathrm{Al}_{2} \mathrm{O}_{3}-\mathrm{SmAlO}_{3}$ eutectic (called A-S) shows a high flexural strength, of the same order of magnitude as for the A-Y-Z ternary eutectic $[18,20]$.

Our previous works focussed on the overall microstructure, mechanical properties and deformation micromechanisms of the systems $\mathrm{Al}_{2} \mathrm{O}_{3}-\mathrm{RE}_{2} \mathrm{O}_{3}(\mathrm{RE}=\mathrm{Y}, \mathrm{Gd})-\mathrm{ZrO}_{2}$, namely $\mathrm{A}-\mathrm{Y}-\mathrm{Z}$ or A-G-Z $[15,21]$. More recently the systems $\mathrm{Al}_{2} \mathrm{O}_{3}-\mathrm{SmAlO}_{3}(\mathrm{~A}-\mathrm{S})$ and $\mathrm{Al}_{2} \mathrm{O}_{3}-\mathrm{SmAlO}_{3}-\mathrm{ZrO}_{2}$ (A-S-Z), revealed a good fracture toughness, higher than those of the A-Y-Z eutectic.

Specific orientation relationships occur between the two main phases that can be modified by the addition of zirconia (Z). For each system a small number of OR's are associated with an isotropic "Chinese script" microstructure. They may be related to the solidification method and the growth rate. Generally one of them is mainly encountered.

The stability of the microstructure and the strength involve interface characteristics, whose analysis is fundamental to understand the final materials properties. Investigations of interfacial features in the as prepared materials are a prerequisite to further studies of interface behaviour during creep.

Some interfaces between alumina and $\mathrm{SmAlO}_{3}$ have been investigated at the atomic level and the creep micromechanisms revealed in the system A-S-Z [19]. 
The present paper will bring more results on the interfacial features in the same system. It will also present the interface structure between alumina and zirconia, in the A-Y-Z system. Some interfaces between alumina and $\mathrm{Y}_{3} \mathrm{Al}_{5} \mathrm{O}_{12}$, and zirconia and $\mathrm{Y}_{3} \mathrm{Al}_{5} \mathrm{O}_{12}$ have also been investigated, in a less detailed manner owing to a slight deviation from the parallelism of the zone axes. A better knowledge of interfacial features in these eutectic oxides could shed light on the role played by interfacial.

The growth of eutectic phases corresponds to interfaces minimum energy configurations, which imposes the growth directions.

\section{Experimental procedure}

The oxide-oxide eutectics were prepared by solidification from the melt by using a floatingzone translation device consisting of an arc-image furnace operating with a $6 \mathrm{~kW}$ xenon lamp providing radiation. The synthesis procedure started with isostatic pressing at $150 \mathrm{MPa}$ of cylinders made from high-purity commercial powders (99.9\%) of $\mathrm{Al}_{2} \mathrm{O}_{3}$ (Baikowski Chimie, France), $\quad \mathrm{Y}_{2} \mathrm{O}_{3}$ (Rhodia, France), $\mathrm{Sm}_{2} \mathrm{O}_{3}$ (Rhodia), and $\mathrm{ZrO}_{2}$ (Th. Goldschmidt Industriechemikalien, Germany). Then, the cylinder bars were consolidated by sintering at $1673 \mathrm{~K}$ before melting. All specimens were solidified at constant rates. They display a cylindrical symmetry with dimensions of about $7 \mathrm{~mm}$ in diameter and $30 \mathrm{~mm}$ in length.

Some samples with same compositions prepared by another crystal growth technique (micro pulling down) [22] were also studied for purposes of comparison.

The cell parameters of each phase were determined by X-ray diffraction and Rietveld refinement on powder samples. Orientation relationships were performed determined by EBSD (Electron Backscatter Diffraction) (detector Oxford) on a Zeiss Merlin microscope.

Conventional Transmission Electron Microscopy (CTEM) was performed on a JEOL2000EX microscope and High Resolution Transmission Electron Microscopy (HRTEM) was performed on two microscopes, a TOPCON ABT002B (resolution $0.18 \mathrm{~nm}$ ) and a Cscorrected ARM200F (resolution $0.85 \mathrm{~nm}$ ). For image simulations we used the software MacTempas developed by Roar Kilaas [23]. 
TEM thin foils were obtained from cut platelets perpendicular to the growth direction, by polishing down to a few micrometres thickness using the tripod technique. A final thinning was performed by gentle ion milling followed by carbon coating.

\section{Results}

\subsection{Interfaces in the alumina/ $\mathrm{Y}_{3} \mathrm{Al}_{5} \mathrm{O}_{12}$ garnet/ zirconia ternary eutectic}

The A-Y-Z ternary eutectic is prepared with $65 \%$ mole $\mathrm{Al}_{2} \mathrm{O}_{3}, 16 \%$ mole $\mathrm{Y}_{2} \mathrm{O}_{3}$ and $19 \%$ mole $\mathrm{ZrO}_{2}$. Cubic zirconia is stabilised by $17 \%$ mole $\mathrm{Y}_{2} \mathrm{O}_{3}$. The cell parameters are as follows: Alumina $(\boldsymbol{a}=0.4759 \mathrm{~nm}, \boldsymbol{c}=1.2999 \mathrm{~nm}), \mathrm{Y}_{3} \mathrm{Al}_{5} \mathrm{O}_{12}(\boldsymbol{a}=1.201 \mathrm{~nm})$, zirconia $(\boldsymbol{a}=0.5165 \mathrm{~nm})$. The eutectic composite solidified at $10 \mathrm{~mm} / \mathrm{h}$ displays a "chinese script" microstructure (Fig. 1). It shows a pronounced grain elongation along the solidification direction [18] The overall microstructure, crystallographic orientation relationships (OR's) and mechanical properties are detailed in previous works $[18,19,21,24]$.

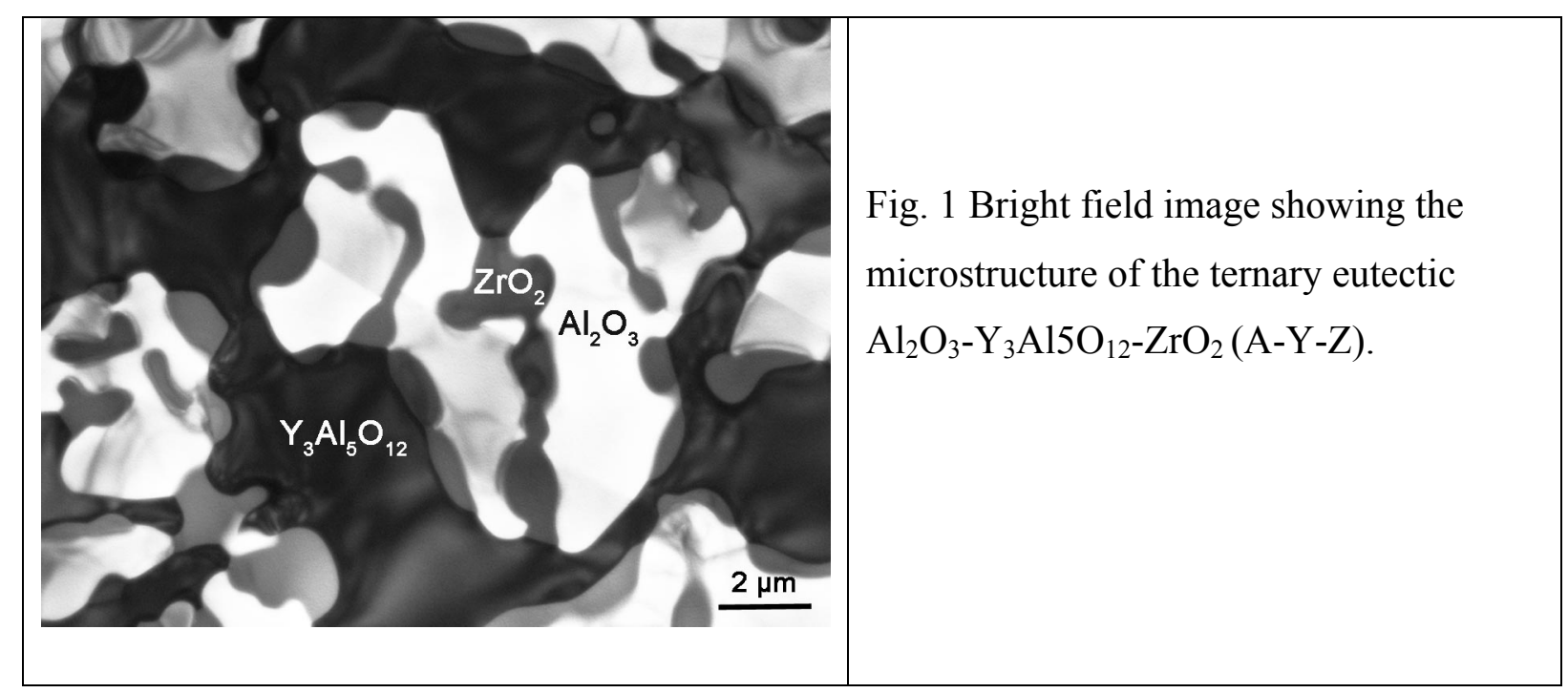

The OR's are defined by parallel growth directions and parallel planes containing the growth direction. Family crystal planes between braces are given with the smallest indices. For specific planes in brackets, the dense planes correspond to the shortest allowed vectors in the diffraction pattern or to planes defined in a HRTEM image.

Specimens prepared by arc-image furnace or micro Pulling Down display the following OR's, where the subscripts "A" stands for alumina, subscript " $\mathrm{Y}$ " for $\mathrm{Y}_{3} \mathrm{Al}_{5} \mathrm{O}_{12}$ and subscript " $\mathrm{Z}$ " for zirconia: 
$[10 \overline{1} 0]_{A} / /[001]_{Y}$,

for the planes, two OR's are encountered between YAG and alumina,

OR1: $\{0001\}_{A} / /\{210\}_{Y}$, or OR2: $\{0001\}_{A} / /\{100\}_{Y}$, the first OR being mainly found

The OR between $\mathrm{A}$ and $\mathrm{Z}$ is always the same and corresponds to the OR determined for binary A-Z eutectic [25] and also for epitaxial growth of Z on A [26]:

$[10 \overline{1} 0]_{A} / /[001]_{Z},\{2 \overline{1} \overline{1} 0\}_{A} / /\{100\}_{Z},\{0001\}_{A} / /\{010\}_{Z}$

The experimental OR is perfect for $\mathrm{A} / \mathrm{Z}$ interfaces and is generally deviated from the perfect OR for $\mathrm{A} / \mathrm{Y}$ and $\mathrm{Z} / \mathrm{Y}$ interfaces. Thus $\mathrm{A} / \mathrm{Z}$ interfaces were more widely investigated. The images are recorded with a zone axis parallel or close to the growth axis.

\subsubsection{Interfaces between alumina and zirconia}

The interfaces between alumina and zirconia phases are rounded at a microscopic level (Fig. 2). At the atomic scale, interfaces are strongly faceted with short facets (length $\leq 7 \mathrm{~nm}$ ), parallel to the above dense planes of both phases. The projection axis is the growth direction. Three types of planes containing the projection axis have been found, the schema in Fig. 3 shows a $\mathrm{Z}$ crystal included in A phase, the dots correspond to lattice sites. The plane $(11 \overline{2} 3)_{A}$ is deviated by $2.2^{\circ}$ from the $(\overline{2} 10)_{Z}$ plane.

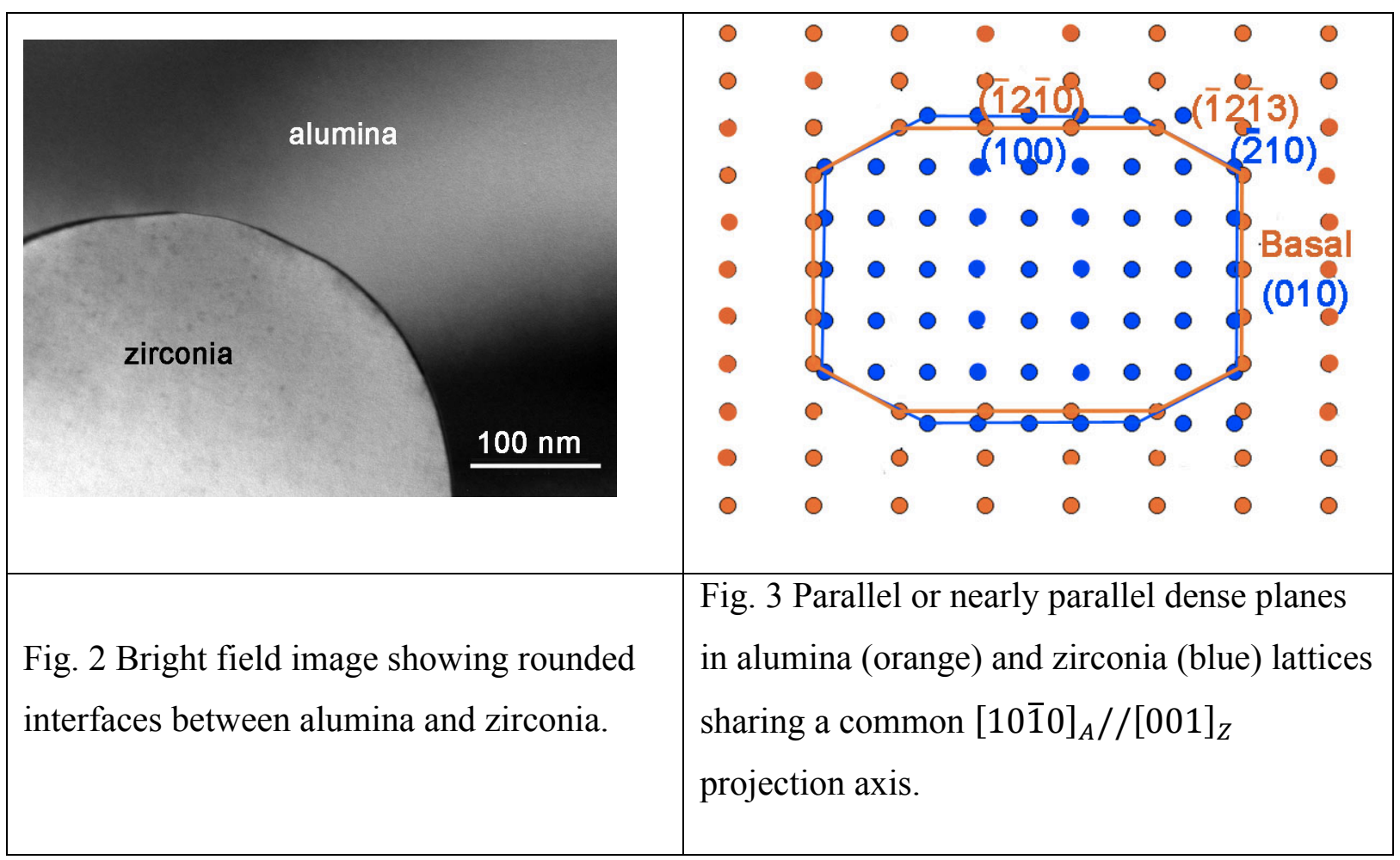


An interface whose facets are parallel to $\{0001\}_{\mathrm{A}} / /\{010\}_{\mathrm{Z}}$ is shown in Fig. 4. In the interface plane, the misfits between parallel dense planes are relatively small, equal to $7 \%$ for $(1 \overline{2} 10)_{A} / /(200)_{Z}$. It is accommodated by dislocations every 13 planes $(1 \overline{2} 10)_{A}$ and 12 $(200)_{Z}$ planes, the residual misfit being equal to $0.3 \%$. The steps have a dislocation character, and are thus called disconnections. The step height corresponds to two (0003) planes in alumina (Fig. 4(b)).

A Burgers circuit around a step is drawn on a constrained dichromatic pattern with a perfect matching of $(1 \overline{2} 10)_{A} / /(200)_{Z}$ (Fig. 4(c)). The Burgers vector has a component along the $y$ direction that induces a rotation between the two crystals of $0.8^{\circ}$, clearly visible in Fig. 4(b). It is worth noticing that the sense of the rotation depends on the step height. Introduire figure 4(d)???

\begin{tabular}{|c|c|c|}
\hline $\begin{array}{l}\text { Zirconia } \\
\text { Navina }\end{array}$ & 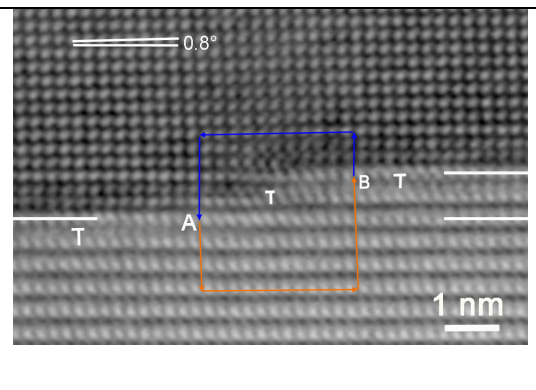 & 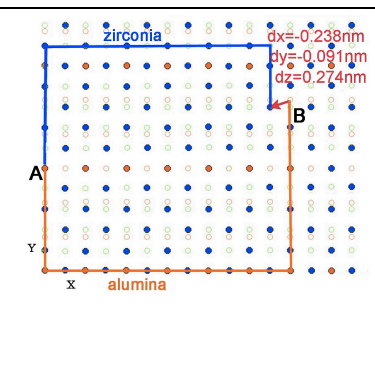 \\
\hline $\begin{array}{l}\text { Fig. 4(a) HRTEM image of an } \\
\text { interface parallel to a basal plane in } \\
\text { alumina and a (020) plane in } \\
\text { zirconia (image Topcon, }[10 \overline{1} 0]_{A} / / \\
{[001]_{Z} \text { projection axis). }}\end{array}$ & $\begin{array}{l}\text { (b) Enlarged view of Fig. 4(a): } \\
\text { Circuit around a step. }\end{array}$ & $\begin{array}{l}\text { Circuit of Fig. 4(b) } \\
\text { reported in a } \\
\text { constrained } \\
\text { dichromatic pattern } \\
\text { (blue: zirconia, } \\
\text { orange: Alumina). }\end{array}$ \\
\hline
\end{tabular}

In Fig. 5, the mean interface plane is tilted by $23^{\circ}$ from the basal plane of $\mathrm{A}$, and presents facets alternately parallel to basal and prismatic $(11 \overline{2} 0)_{A}$ planes. For this specific orientation, the misfits for each pair of planes $\left((0006)_{A} / /(020)_{Z}\right.$ and $\left.(1 \overline{2} 10)_{A} / /(200)_{Z}\right)$ are located at the same place at the upper edges of the facets that accommodate both misfits. 
A 2D atomic model is superimposed on the image (Fig. 5(b)). The white dots correspond to $\mathrm{Zr}$ columns in $\mathrm{Z}$ and are close to oxygen columns in $\mathrm{A}$. The interface is centred on oxygen columns, as expected, considering that planes parallel to the interface are polar planes for each structure. Strong variations in the contrast along interfaces occur in all images, probably due to internal stresses resulting, in part, from the sample preparation by mechanical thinning. Contrast simulations required to add a small tilt angle to the electron beam that introduced a dissymmetry in the contrast of oxygen columns.

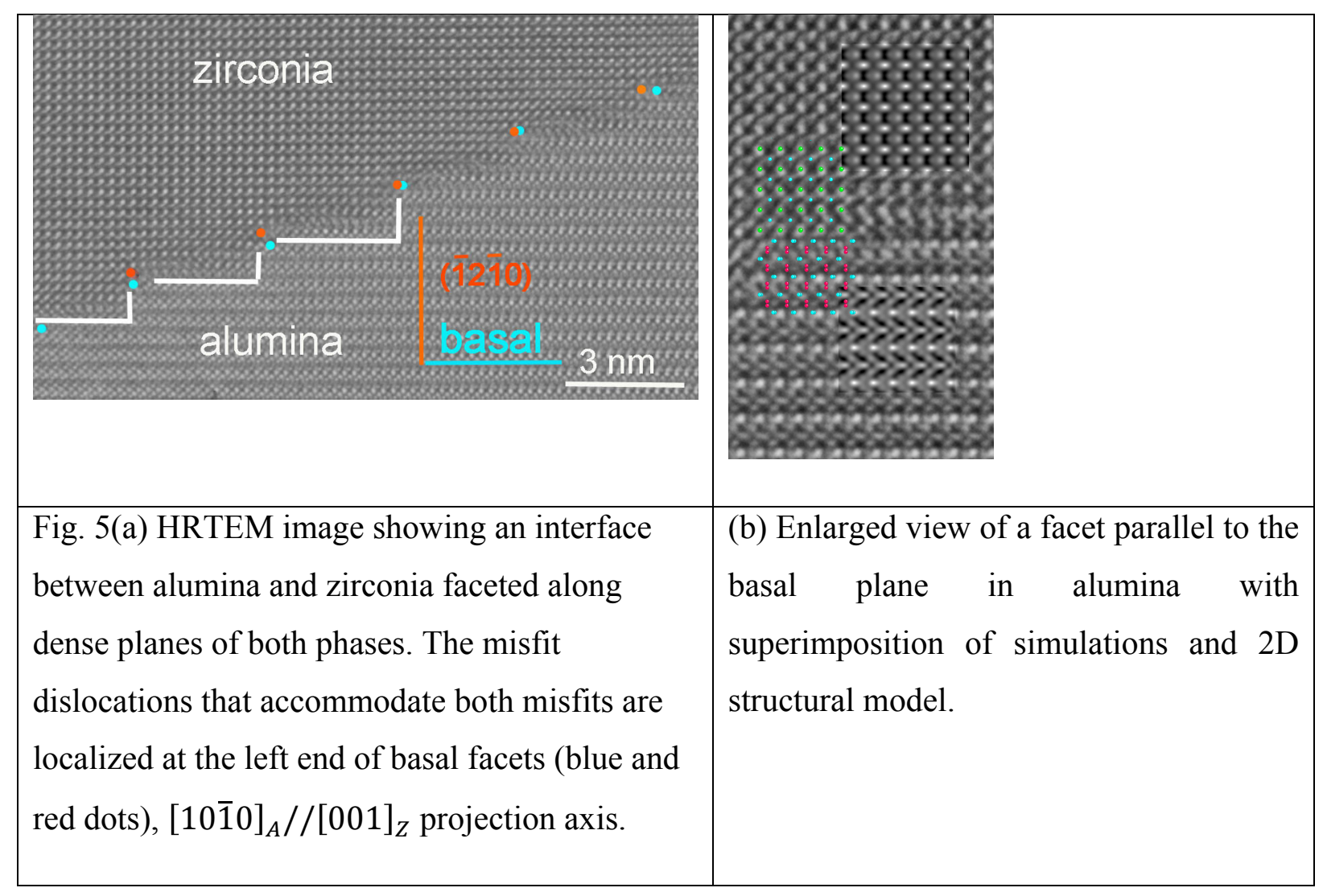

Fig. 6 shows an example of the second type of interfaces parallel to dense planes of both crystals. The facets (length $\approx 4.5 \mathrm{~nm}$ ) are parallel to the prismatic $(11 \overline{2} 0)_{A}$ plane and to $(200)_{Z}$. There is a nearly perfect matching between six (0006) planes in A and five (020) planes in $\mathrm{Z}$, the residual misfit is small equal to $0.7 \%$. The steps have a disconnection character, a circuit around the step reveals a component (perpendicular to the interface) of the Burgers vector that implies a rotation of $0.7^{\circ}$ between the two phases, experimentally observed. It is worth noting that the sense of the rotation is opposite to that found in the previous case. The image in Fig. 6(b) is close to the zero focus, and the white dots correspond to oxygen atomic columns in both phases. The interface is centred to oxygen columns that show a corrugated arrangement as in the A phase. An accurate determination of the interface 
structure requires to image the interface with another zone axis. Such experiment has been performed previously in a binary A-Z eutectic composite [25]. In Fig. 7, the projection axis is [0001]. The interface presents facets (length $\approx 5.2 \mathrm{~nm}$ ) separated by monoatomic steps. The white dots correspond to the cations columns in both phases and the interface is centred on oxygen columns. The facet structure is incoherent, as shown by the small templates superimposed on the image. Thus there is no preferred interfacial structure along the direction $[10 \overline{1} 0]_{A}$. We also note that $\{30 \overline{3} 0\}_{A}$ are not dense planes of $\mathrm{A}$.

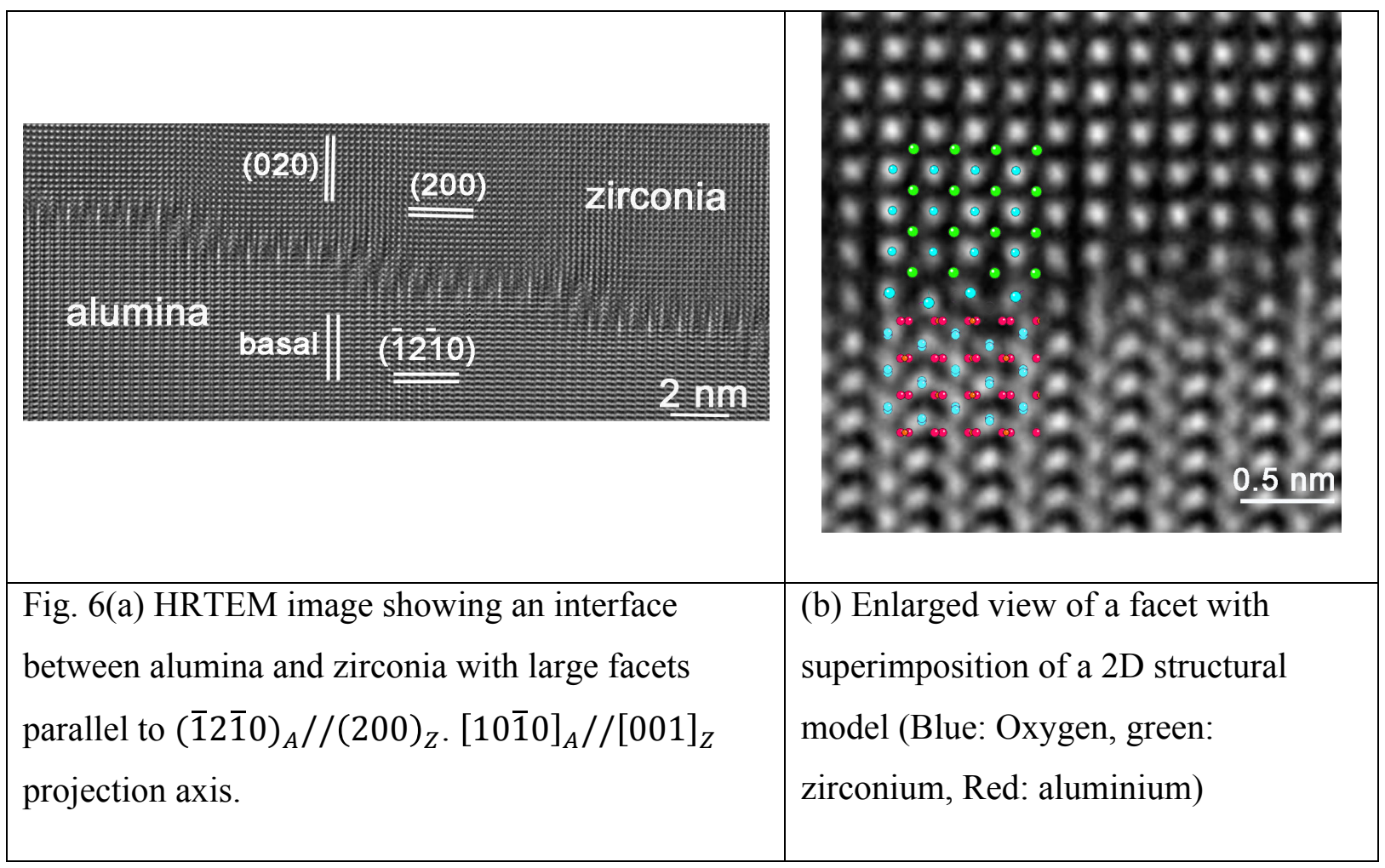

\begin{tabular}{|c|c|}
\hline 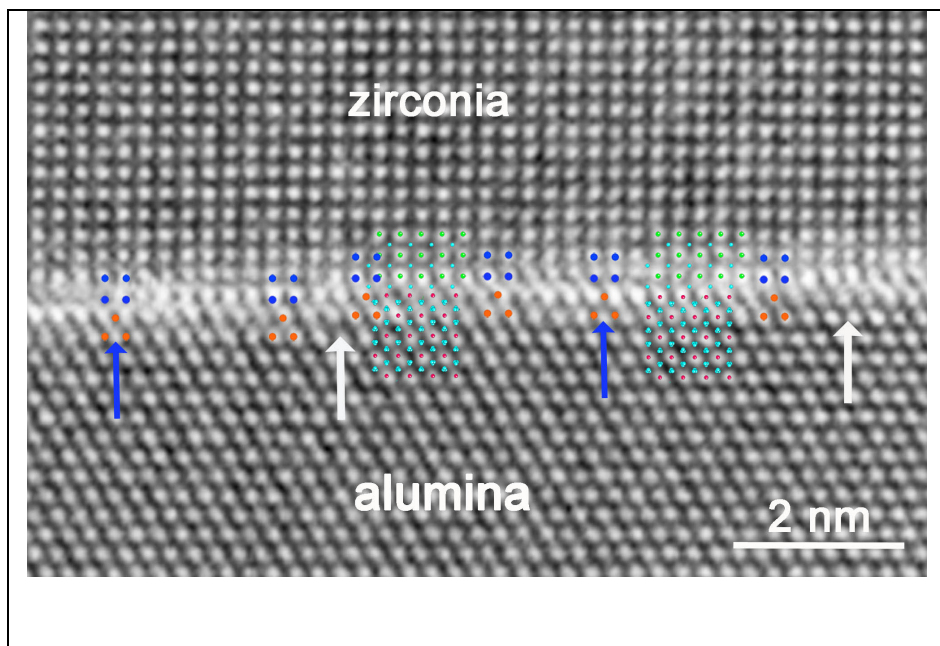 & $\begin{array}{l}\text { Fig. } 7 \text { HRTEM image showing an } \\
\text { interface between alumina and } \\
\text { zirconia with large facets parallel to } \\
(\overline{1} 2 \overline{1} 0)_{A} / /(200)_{Z} \text { in a binary } \\
\text { eutectic. The projection axis is [0001] } \\
\text { in alumina. The white arrows indicate } \\
\text { the steps. The small templates (blue } \\
\text { and orange dots) reveal the } \\
\text { incoherent character of the interface. }\end{array}$ \\
\hline
\end{tabular}


Fig. 8 shows an interface with facets alternately parallel to basal and (12 123$)$ planes of A (facet length $\approx 4 \mathrm{~nm}$ ). The $(\overline{1} 2 \overline{1} 3)$ plane is the third densest plane of $\mathrm{A}$ for this projection axis and is not parallel to the (240) plane in Z. The dislocations that accommodate the misfit between $(1 \overline{2} 10)_{A}$ and $(200)_{Z}$ are located in the middle of the $(\overline{1} 2 \overline{1} 3)$ facet, the basal facets showing perfect coherency. This last example suggests a preferential selection of dense A planes during the eutectic growth.

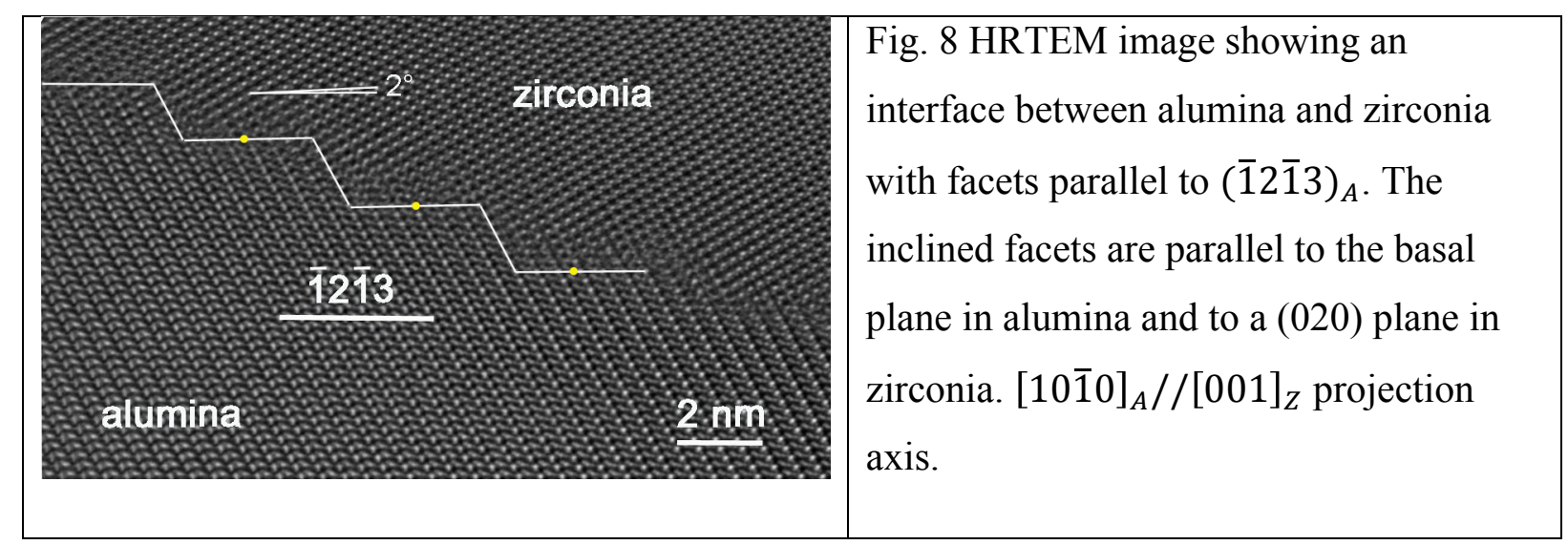

\subsubsection{Interfaces between alumina (A) and $\mathrm{Y}_{3} \mathrm{Al}_{5} \mathrm{O}_{12}$ garnet $(\mathrm{Y})$}

The localisation of zirconia at the interfaces between $\mathrm{A}$ and $\mathrm{Y}$ phases made challenging a thorough analysis of these interfaces. The OR1 defined above between A and Y is mostly encountered in ternary eutectics, and is different from the OR reported in binary A-Y eutectics, $[10 \overline{1} 0]_{A} / /[110]_{Y}$, and $\{0001\}_{A} / /\{100\}_{Y}[18,27]$.

Interfaces are preferentially parallel to dense planes in the Y phase. In Fig. 9, the interface presents large facets parallel to a $\{020\}$ plane in the $\mathrm{Y}$ phase and far from a dense plane in A. The small facets are parallel to the A basal plane.

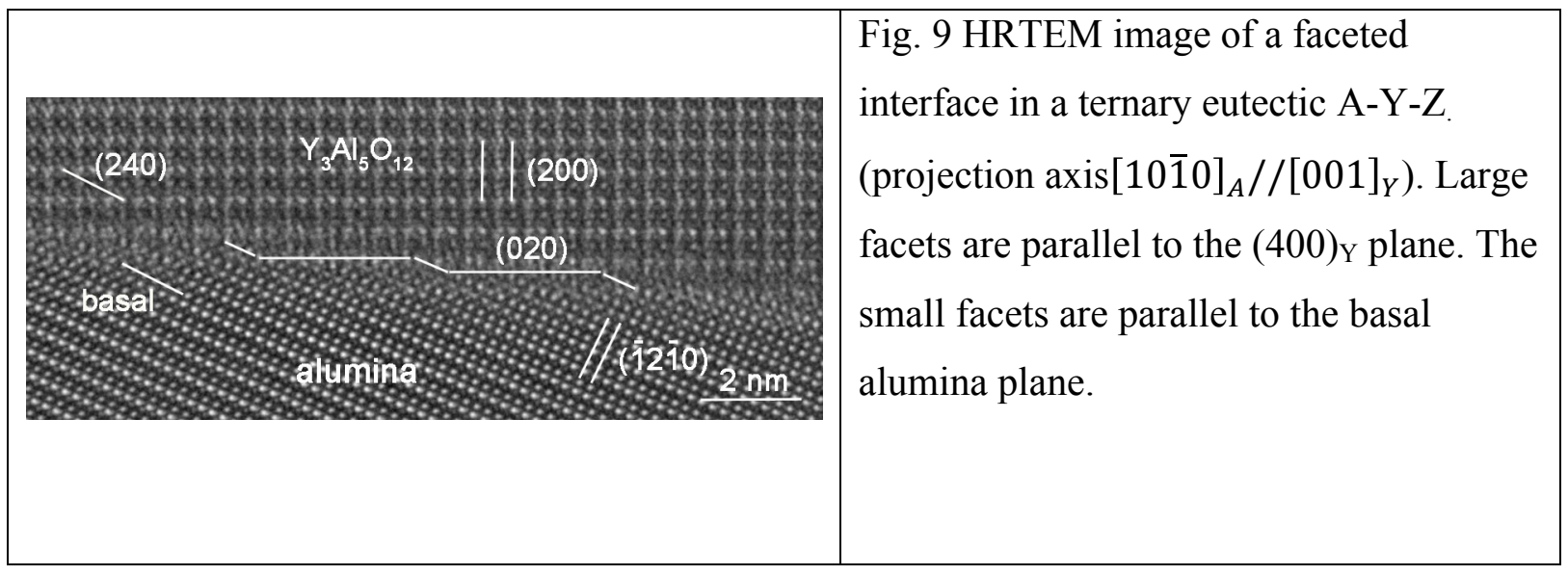


The fact that the observed OR between $\mathrm{Y}$ and $\mathrm{A}$ changes when $\mathrm{Z}$ is added could be related to a preferred OR between $\mathrm{Y}$ and $\mathrm{Z}$.

\subsubsection{Interfaces between $\mathrm{Y}_{3} \mathrm{Al}_{5} \mathrm{O}_{12}$ garnet $(\mathrm{Y})$ and Zirconia $(\mathrm{Z})$}

\section{Léo: pour ce paragraphe, je vais metre explicitement chaque plan}

The interfaces between $\mathrm{Y}$ and $\mathrm{Z}$ are straight or faceted. In most cases the orientation deviates from the perfect OR. The dichromatic complex in Fig. 10 reveals the parallelism of $\{420\}_{\mathrm{Y}}$ and $\{200\}_{z}$ planes, which display a small misfit (4\%). Thus interface planes parallel to dense planes $\{420\}_{\mathrm{Y}} / /\{200\}_{\mathrm{Z}}$ could occur, as well as $\{400\}_{\mathrm{Y}} / /\{420\}_{\mathrm{Z}}$ planes.

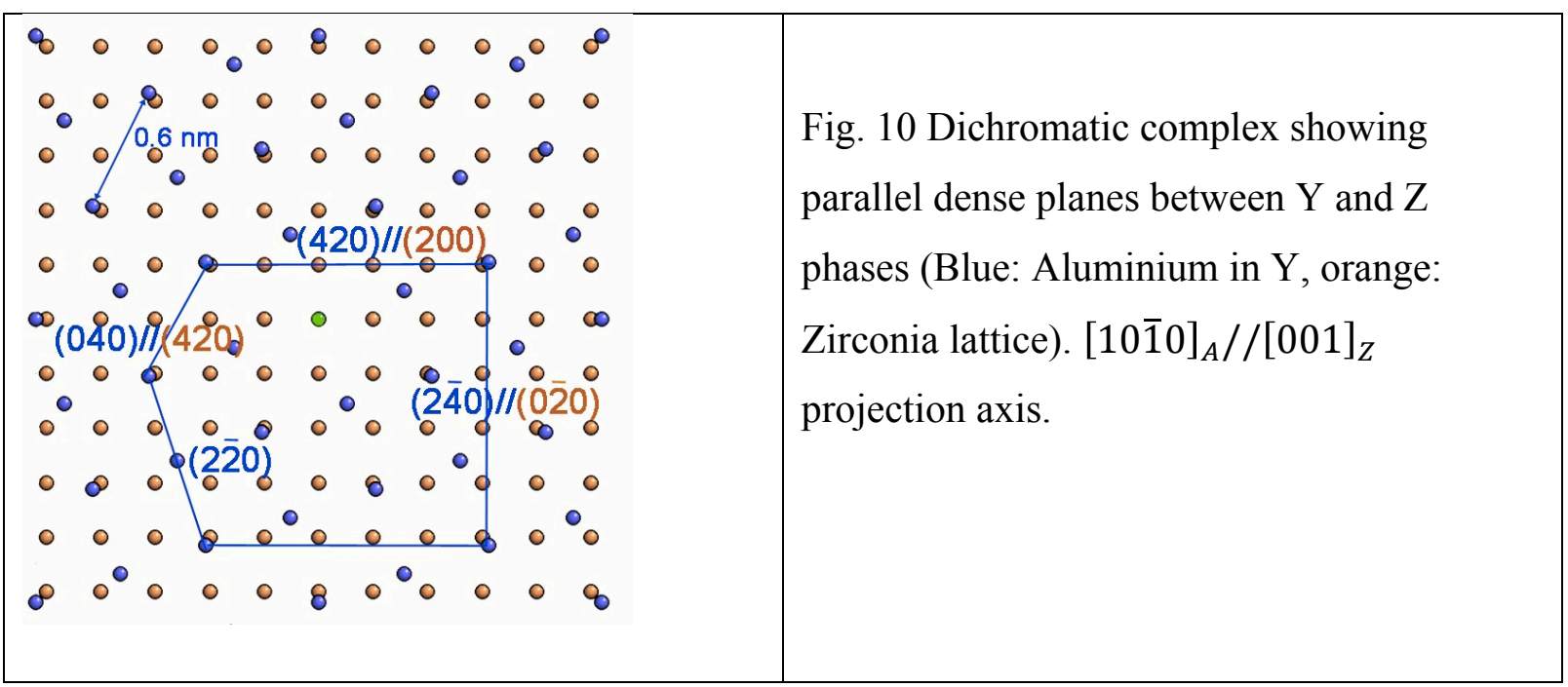

A $(240)_{Y}$ plane is effectively parallel to a $(200)_{Z}$ plane in case of a perfect OR between phases (Fig. 11). The small misfit (4\%) is accommodated by dislocations. For all other cases, which present a deviation from a perfect OR, interfaces are parallel to a dense plane of one crystal, either $\{400\}$ (Fig. 12), $\{220\}$ or $\{420\}$ of the Y phase, or $\{200\}$ or $\{210\}$ (Fig. 13) of Z. In summary, these features are similar as those encountered for Y/A interfaces. 


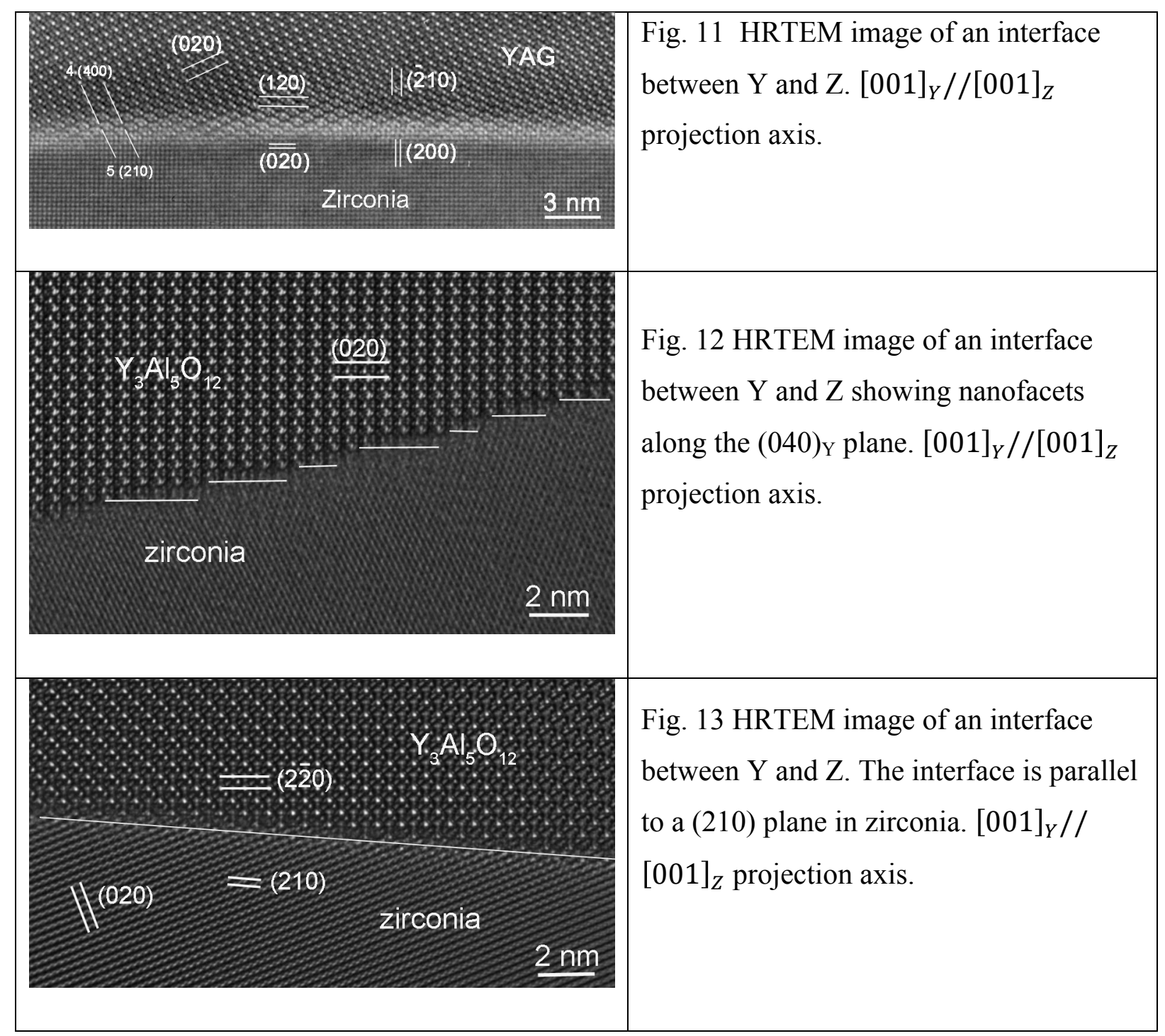

\subsection{Interfaces between alumina (A) and $\mathrm{SmAlO}_{3}$ perovskite (S) in the ternary eutectic A-}

\section{S-Z}

The overall microstructure is perfectly isotropic, displaying a similar microstructure in all space directions (Fig. 14). The A and S phases have similar sizes, the $\mathrm{Z}$ phase being dispersed along the interfaces or included in the A phase. The cell parameters are as follows: alumina $(\boldsymbol{a}=0.4758 \mathrm{~nm}, \boldsymbol{c}=1.2998 \mathrm{~nm})$, perovskite $(\boldsymbol{a}=0.5282 \mathrm{~nm}, \boldsymbol{b}=0.7469 \mathrm{~nm}, \boldsymbol{c}=0.5285 \mathrm{~nm})$, zirconia $(\boldsymbol{a}=0.5203 \mathrm{~nm})$. The growth direction of $\mathrm{A}$ is not unique as in $\mathrm{A}-\mathrm{Y}-\mathrm{Z}$ eutectics, and the $<11 \overline{2} 0>$ may occur, rarely found in the A based eutectics. 


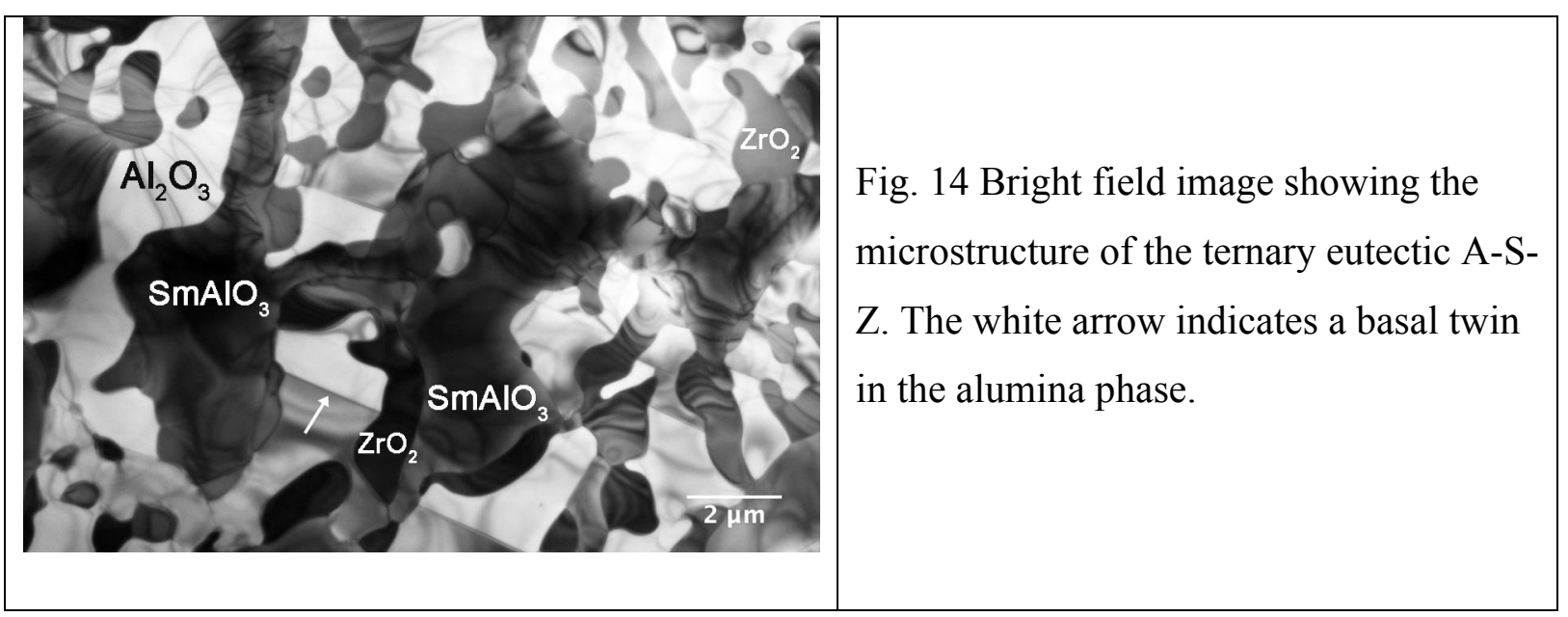

The following OR's are mainly found:

$<11 \overline{2} 0>_{\mathrm{A}} / /<001>_{\mathrm{S}}$ or $<100>_{\mathrm{S}}$ and $<10 \overline{1} 0>_{\mathrm{A}} / /<011>_{\mathrm{S}}$ or $<110>_{\mathrm{S}}$

with common orientation relationships between the three eutectic phases whatever the growth direction: $\{0001\}_{\mathrm{A}} / /\{110\}_{\mathrm{S}} / /\{100\}_{\mathrm{Z}}$

The different areas analysed by HRTEM in several thin foils always reveal the OR $<11 \overline{2} 0>_{\mathrm{A}} / /$ $<001>_{S}$ or $<100>_{S}$ that is also found in the binary eutectic. The $S$ phase has a pseudotetragonal symmetry, with $\boldsymbol{a}$ and $\boldsymbol{c}$ parameters nearly identical. Several domains with various orientations are found, even within a same S crystal, owing to the cubic/orthorhombic phase transformation that occurs at high temperature.

Only A/S interfaces could be analysed. Although the OR between A and Z is perfect, the projection axis $<11 \overline{2} 0>_{\mathrm{A}} / /<100>_{\mathrm{S}}$ is not parallel to a dense direction in $\mathrm{Z}$.

The A phase presents two orientation variants related by the basal twin orientation relationship, such that the growth axis is parallel to $[2 \overline{1} \overline{1} 0]_{A}$ or to $[\overline{2} 110]_{A}$ (Fig. 14). Two dichromatic patterns reported in Fig. 15 correspond to the orientation relationships $[\overline{2} 110]_{A} / /$ $[100]_{S}$ and $(0001)_{A} / /(0 \overline{1} 1)_{S}$ or $[2 \overline{1} \overline{1} 0]_{A} / /[100]_{S}$ and $(0001)_{A} / /(0 \overline{1} 1)_{S}$ and show the interpenetrated lattices of the two phases. Dense planes of each phase nearly parallel are highlighted in Fig. 15(a). They present close interplanar spacings. The best fit occurs for the basal plane $(0003)_{\mathrm{A}}$ in $\mathrm{A}$ parallel to $(01 \overline{1})_{\mathrm{S}}(0.432 \mathrm{~nm}$ and $0.431 \mathrm{~nm}$ respectively). The highest misfit occurs for the $(01 \overline{1} 2)_{A} / /(020)_{S}$, equal to $7 \%$. The angles between parallel planes are at most equal to $3^{\circ}$. Thus the two lattices are nearly coincident in the projection plane. 


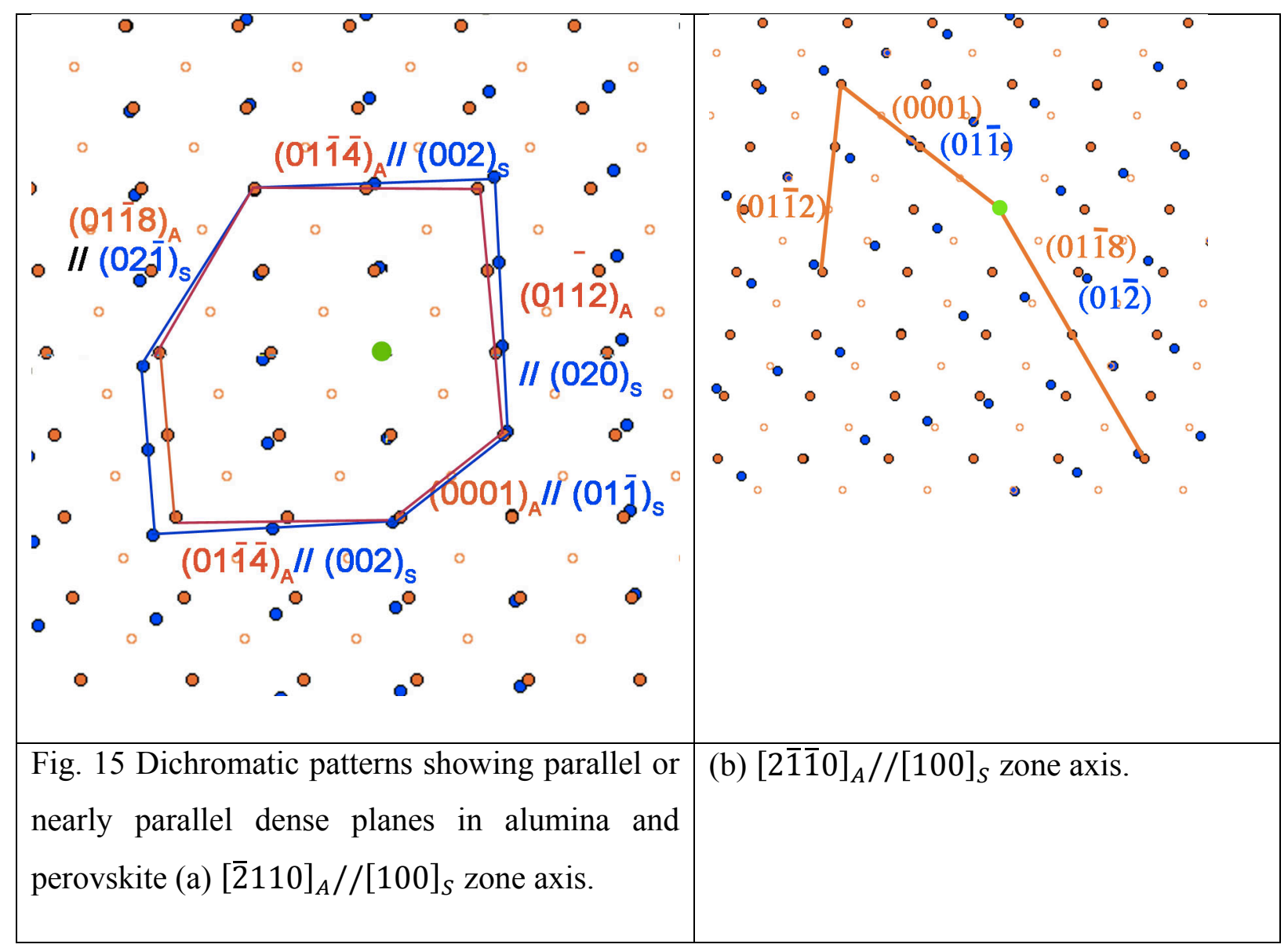

All interfaces mentioned in Fig. 15(a) have been observed. Interfaces parallel to $(01 \overline{1} \overline{4})_{A} \approx$ $/ /(002)_{S}$ and to $(01 \overline{1} 8)_{A} \approx / /(02 \overline{1})_{S}$ have been described in a previous paper [19]. The first one present facets strictly parallel to both dense planes and centred on oxygen columns (facet length $4.8 \mathrm{~nm})$, the second one is straight and is parallel to the A plane $(01 \overline{1} 8)_{A}$. The examples shown below allow to go further in the knowledge of interfacial features. Fig. 16(a) shows a strongly faceted interface (facet length $5.8 \mathrm{~nm}$ ), the step height corresponds to three $(01 \overline{1} 2)_{A}$ A planes. The angle between dense planes nearly parallel to the interface is $2.9^{\circ}$ and corresponds to the theoretical value. The facets present a nearly perfect parallelism of dense planes in each phase, and accommodate the misfit between vertical planes $(01 \overline{1} \overline{4})_{A} \approx$ $/ /(002)_{S}$. The same features occur for the faceted interface $(01 \overline{1} \overline{4})_{A} \approx / /(002)_{S}[19]$. An analysis in the dichromatic complex reveals that the interface passes through the coincidence sites (Fig. 16(b)). 


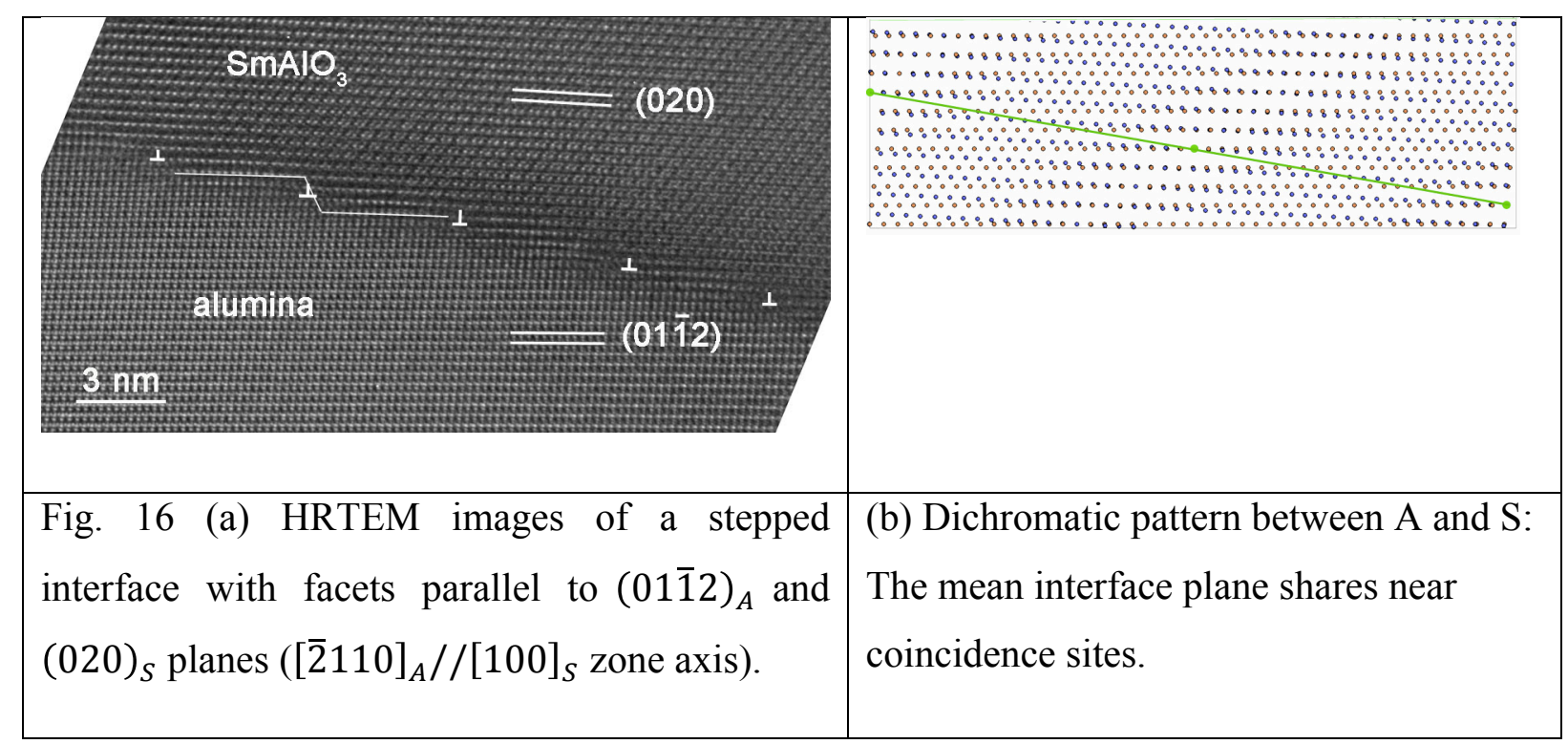

Finally an interface parallel to $(0001)_{A} / /(0 \overline{1} 1)_{S}$ (not shown) is straight; a one dislocation array accommodates the misfits between the dense planes across the interface. This interface corresponds to the parallelism of planes in the orientation relationship and is also found for the variant orientation of $\mathrm{A}[2 \overline{1} \overline{1} 0]_{A} / /[100]_{S}$ as illustrated below.

In Fig. 15(b), the dichromatic pattern for the second OR between A and S reveals only two sets of dense planes parallel in both phases, $(0001)_{A} / /(01 \overline{1})_{S}$ and $(01 \overline{1} 8)_{A} / /(01 \overline{2})_{S}$. These two interfaces have been found, a third one (not shown) displays short facets $(2 \mathrm{~nm}$ length) parallel to the $(01 \overline{1} 2)_{A}$ in $A$ and far from any dense plane in $S$.

The interface $(0001)_{A} / /(01 \overline{1})_{S}$ displays facets $(2.7 \mathrm{~nm}$ length) separated by steps, the step height being one interplanar distance (Fig. 17). An analysis in the dichromatic complex reveals that the interface passes through the near coincidence sites (Fig. 17(b)). The facets show a perfect agreement between dense planes across the interface and the steps accommodate the misfit, as already found for the $(01 \overline{1} 2)_{A} / /(020)_{S}$ interface.

The misfits between parallel or nearly parallel dense planes on each side of the interface plane are smaller than $11 \%$ for all studied interfaces. 


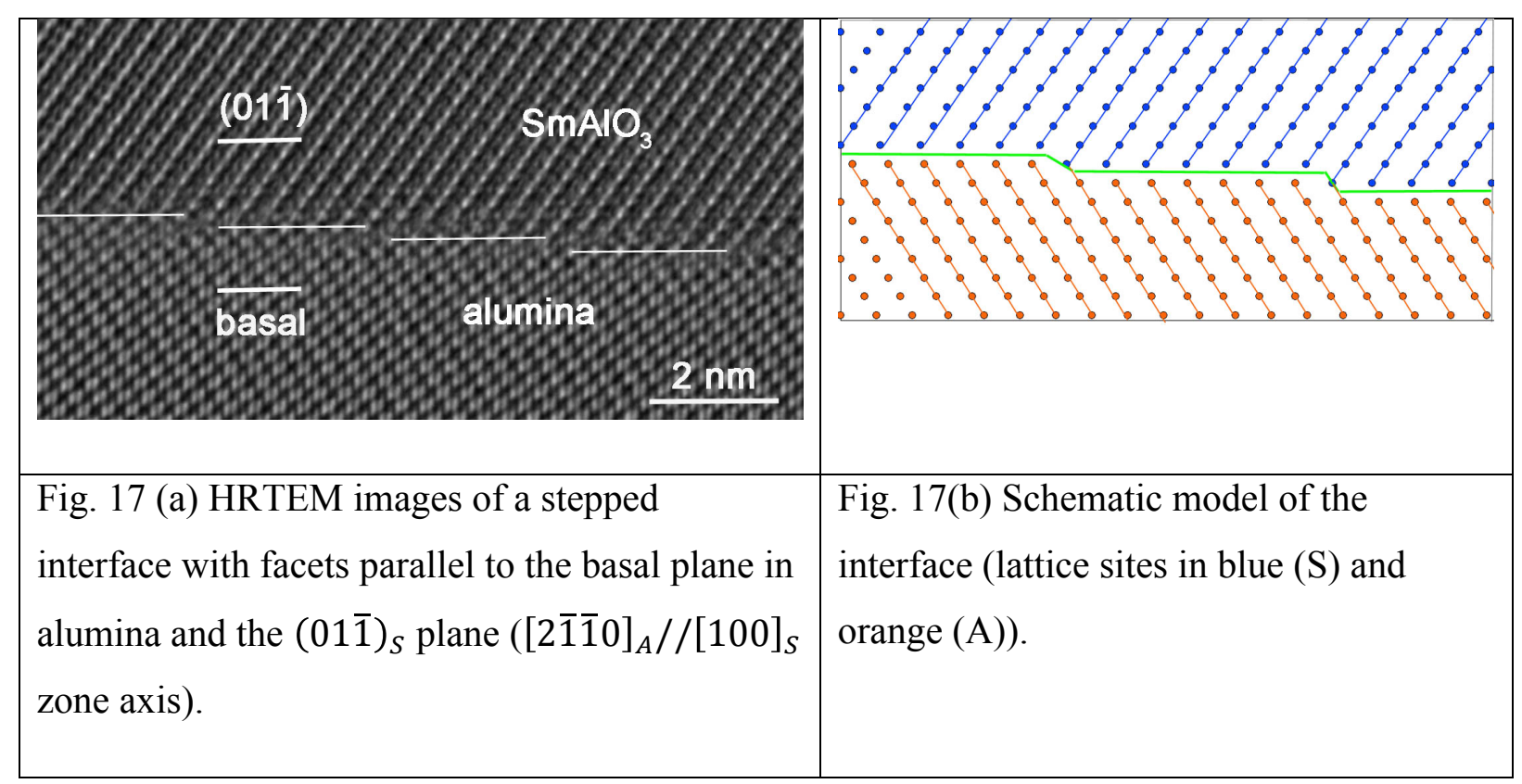

A large facet is parallel to the $(01 \overline{1} 8)_{A}$ plane, at 2 degrees from $(01 \overline{2})_{S}$, confirming that faceting occurs preferentially along dense A planes (Fig. 18).

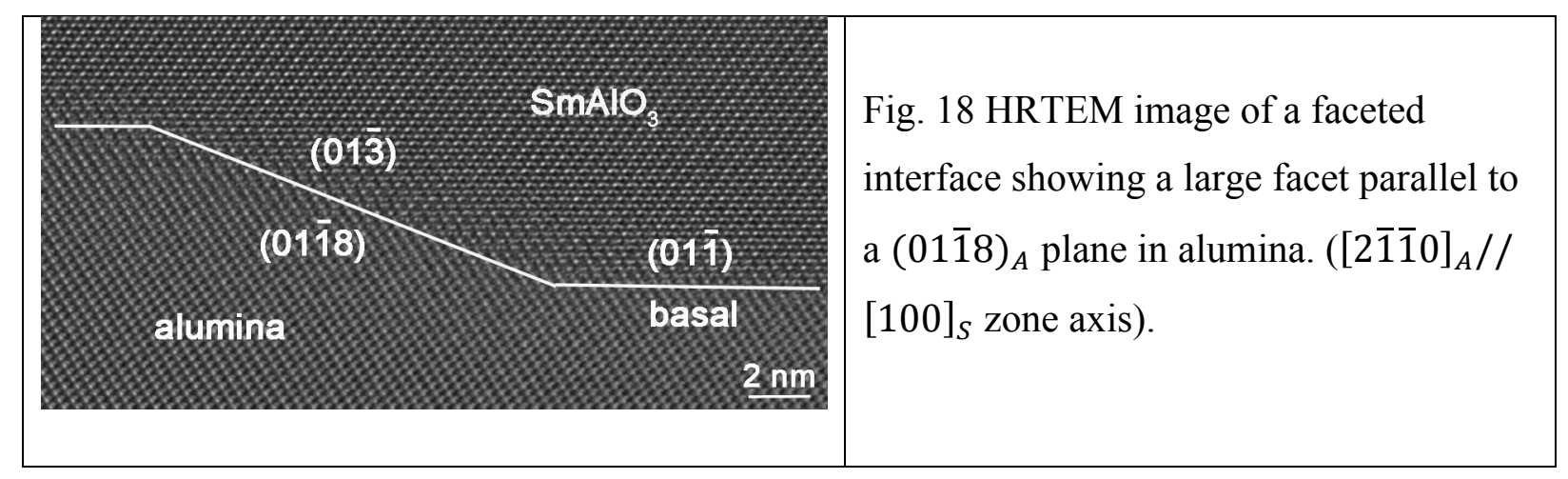

\section{Discussion}

Interfaces play a predominant role in the growth features and final microstructure of directionally solidified eutectics. As a matter of fact, the growth directions $[10 \overline{1} 0]_{A}$ and $[001]$ or $[110]_{Y}$ most often encountered are different from the preferred growth directions in single crystal, $[0001]_{\mathrm{A}}$ and $[111]_{\mathrm{Y}}$. In A-Y-Z the presence of $\mathrm{Z}$ modifies the OR's, in particular the parallel planes. Binary eutectics show a parallelism of densest planes $\{0001\}_{\mathrm{A}}$ and $\{112\}_{\mathrm{Y}}$, although ternary eutectics show a parallelism of $\{0001\}_{\mathrm{A}}$ and $\{210\}$ or $\{100\}_{\mathrm{Y}}$ planes. This is in agreement with a simultaneous growth of the three phases, also present with the A-S-Z eutectics. Several OR's are encountered between A and S, some of them being similar in 
binary and ternary eutectics. The OR's between the three phases are perfect, at variance with the $\mathrm{A}-\mathrm{Y}-\mathrm{Z}$ eutectic. Besides, the $\mathrm{A} / \mathrm{Z}$ OR is not modified by $\mathrm{Y}$ addition, although it is modified when $\mathrm{S}$ is present. The discussion attempts to understand some of these features by considering possible occurrence of interfacial order.

\subsection{Interfaces in A-Y-Z eutectics}

Previous works on binary or ternary eutectic composites with various orientation relationships are summarized as follows: At first the deviation from a perfect OR between Y and A is most often present, it increases with the growth rate. Addition of $\mathrm{Z}$ modifies the overall morphology of interfaces between phases, from straight interfaces in binary eutectics to more curved interfaces in ternary eutectics. At the atomic scale, the interfaces between $\mathrm{Y}$ and $\mathrm{A}$ may be wavy $[28,29]$. In binary eutectics straight interfaces or large facets are parallel to densest planes $\{0001\}_{\mathrm{A}} / /\{112\}_{\mathrm{Y}}[30,31]$. In ternary eutectics, facets are parallel to Y planes $\{400\}$ (this work), $\{220\}[28]$ or $\{112\}[30,31]$, most often not parallel to dense planes of alumina. Locally a parallelism of small facets prismatic $\{11 \overline{2} 0\}_{A} / /\{220\}_{Y}$ is observed [29]. In two cases the interface has a tendency to facet on basal A plane, regardless of the orientation of the Y phase $[28,30]$.

The dichromatic pattern between $\mathrm{Y}$ and A phases does not reveal a preferred near coincidence between dense planes or directions for the first OR. Even for the OR2, it was noticed that a disregistry value corresponding to a residual misfit for a close coincidence between $n$ planes in one phase and $(n+1)$ planes in the other phase is high for interfaces A/Y [32]. The Y phase seems to facet along its dense growth faces.

It has been shown that a small misorientation from the exact, high-symmetry OR improves the lattice coincidence density between the fiber and matrix lattices in the system $\mathrm{LaB}_{6}-\mathrm{ZrB}_{2}$ [33]. In case of growth of spinel $\mathrm{MgAl}_{2} \mathrm{O}_{4}$ on alumina, a rotation of $5^{\circ}$ around an axis contained in the interface plane induces a perfect parallelism of $(1 \overline{1} 0 \overline{4})_{A} / /(400)_{\text {spinel }}$ across the interface [34]. For the OR1 defined above, a rotation of $4.3^{\circ}$ between growth axes around $[1 \overline{2} 10]_{A}$ would lead to a parallelism of dense planes $\{\overline{1} 012\}_{A}$ and with a $7 \%$ misfit. No image with such a projection axis is available. Moreover, various deviation angles occur according to the solidification method and the growth rate, thus no specific preferred interface seems to be found from an energetic point of view. 
The fact that the observed OR1 between $\mathrm{Y}$ and $\mathrm{A}$ changes when $\mathrm{Z}$ is added could be related to a preferred OR between $\mathrm{Y}$ and $\mathrm{Z}$, as suggested by the good coincidence between dense planes of both phases for this OR.

Interfaces $\mathbf{Y} / \mathbf{Z}$ are parallel to dense planes of $\mathrm{Y}$, or to dense planes of $\mathrm{Z}$. It is shown that a near coincidence does occur between $\mathrm{Y}$ and $\mathrm{Z}$, but the parallelism of corresponding dense planes is observed only in a one case. Previous works also found faceted or straight interfaces $\{200\}_{\text {LnAG }}[32,35,36]$ or $\{210\}_{\mathrm{Y}}$ [29]. In one case $(020)_{\mathrm{Z}}$ is close to $(040)_{\mathrm{Y}}$ [32]. In most cases, this near coincidence is not maintained during growth. This is expected from the systematic perfect OR between A and Z. However it could play a role in the OR selection between $\mathrm{Y}$ and $\mathrm{A}$ at the beginning of solidification.

Interfaces $\mathbf{A} / \mathbf{Z}$ show a parallelism of densest planes of both phases, $(11 \overline{2} 0)_{A}$ and basal $\mathrm{A}$ planes being parallel to $\{200\}$ planes in Z. The OR's probably results from the building of low energy interfaces: It is also observed in binary eutectic, and for epitaxial growth of $\mathrm{Z}$ on basal and prismatic planes of sapphire $[25,26]$. The common feature observed for these interfaces is a similar stacking sequence on both sides of the interfaces consisting in alternate cationic and anionic planes or layers with close interplanar distances $\left(\mathrm{d}(11 \overline{2} 0)_{A}=0.238 \mathrm{~nm}\right.$, $\left.\mathrm{d}(200)_{\mathrm{Z}}=0.257\right)$. The oxygen planes located at the interface allows the transition between both structures, leading to compatible interatomic distances and the local electroneutrality at the interface.

As a result from the $\mathrm{Z}$ phase morphology, most interfaces are curved and interfaces are strongly faceted. The disconnections present at the facet edges induce a rotation of the crystal and thus angular incompatibilities that must be accommodated. Disconnections are introduced to relieve the coherency strain on the terraces. The rotation sense and value depend on the step height and facet length and involve a minimisation of defect energy.

For the other interface planes, only the $\{11 \overline{2} 3\}$ plane of $A$ has been found, the third densest plane parallel to the projection axis. The plane $\{210\}$ in $\mathrm{Z}$ is not parallel to the interface plane. It is assumed that the $\mathrm{Z}$ adapts its orientation with its densest planes parallel to dense planes of A.

4.2 Interfaces in the A-S-Z eutectic 
In the ternary eutectic A-S-Z, the orientation relationship between $\mathbf{A}$ and $\mathbf{Z}$ is less favourable. No image of the interfaces $\mathrm{A} / \mathrm{Z}$ could be obtained at the atomic scale owing to an orientation of the $\mathrm{Z}$ phase not suitable for high resolution. However, some comments can be made on the experimental orientation relationship found by EBSD, which occurs systematically whatever the orientation relationship between A and S:

$[10 \overline{1} 0]_{A} / /[011]_{Z},\{1 \overline{2} 10\}_{A} / /\{0 \overline{2} 2\}_{Z},\{0001\}_{A} / /\{020\}_{Z}$

The parallelism between basal planes of $\mathrm{A}$ and $\mathrm{Z}$ is common to all found alumina/zirconia OR's. In the A-S-Z eutectic, the misfit between $(1 \overline{2} 10)_{A}$ and $(0 \overline{2} 2)_{Z}$ planes is $26 \%$, larger than the misfit between parallel $(1 \overline{2} 10)_{A}$ and $(002)_{Z}$ planes in the A-Y-Z eutectic. Moreover the $\{220\}$ planes are not polar planes. From these geometrical arguments it can be assumed that the $\mathrm{A} / \mathrm{Z}$ interfaces are probably more energetic in the $\mathrm{A}-\mathrm{S}-\mathrm{Z}$ eutectic, and that $\mathrm{Z}$ modifies its OR with A to better adapt the S phase.

Various OR's have been found in the A-S-Z system. However, whatever the OR, the parallelisms between following planes between $\mathbf{S}$ and $\mathbf{Z}$ are observed: $\{200\}_{\mathrm{Z}} / /\{220\}_{\mathrm{S}}$ and $\{022\}_{\mathrm{Z}} / /\{121\}_{\mathrm{S}}$. A near coincidence occurs in the $\{022\}_{\mathrm{Z}} / /\{121\}_{\mathrm{S}}$ interface plane with a parallelism of the densest planes $(\overline{1} \overline{1} 1)_{Z} / /(101)_{S}$ (Fig. 19). $5(\overline{1} \overline{1} 1)_{Z}$ match $4(202)_{S}$, with a residual misfit of $0.26 \%$, and $5(200)_{\mathrm{Z}}$ match $6(220)_{\mathrm{S}}$, with a residual misfit $0.3 \%$.

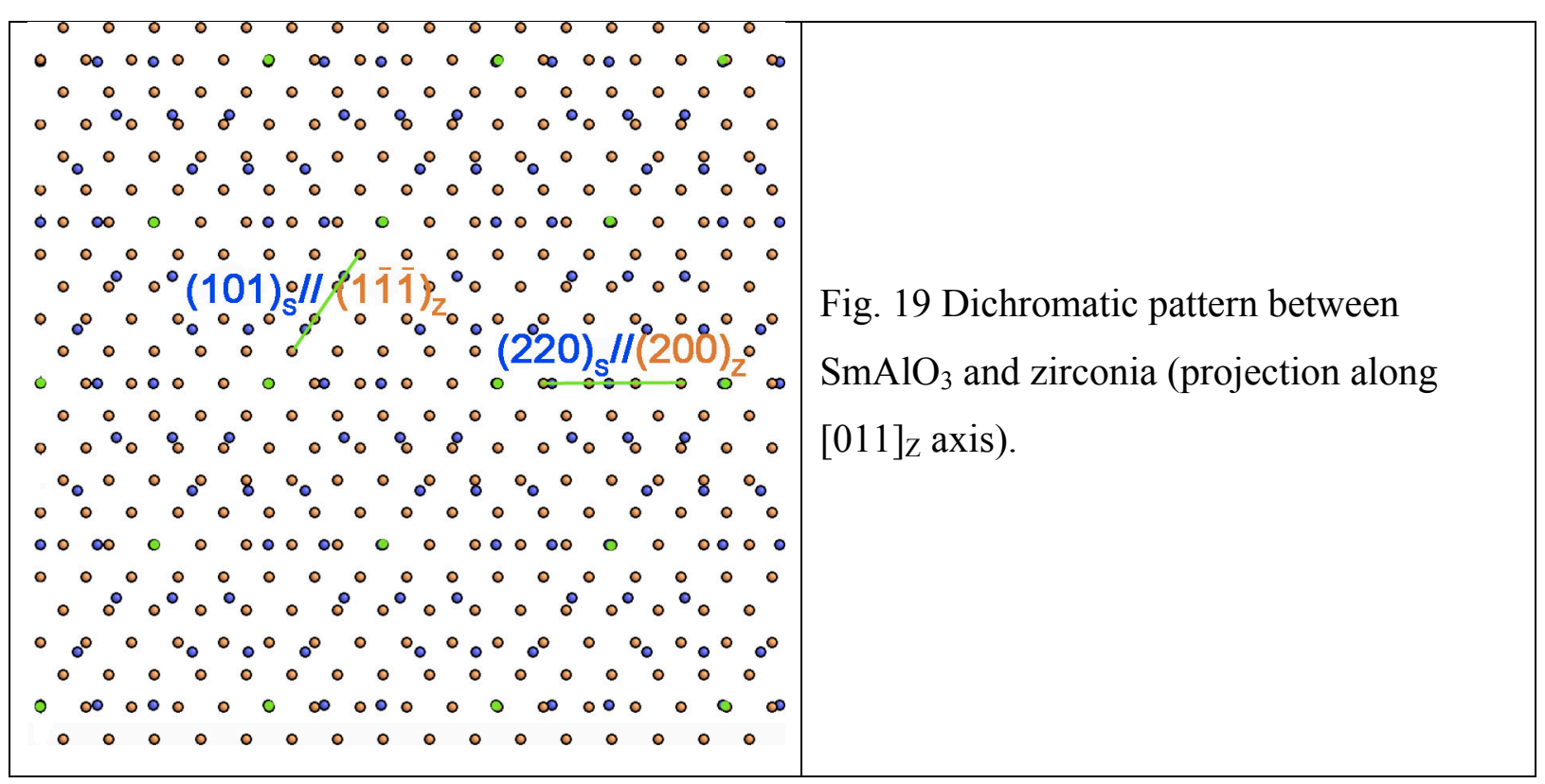


The systematic parallelism of dense planes of both crystals and the crystallographic characteristics could explain the change in the A/Z OR when $\mathrm{S}$ is present. It is worth noting that the relation $\{200\}_{\mathrm{Z}} / /\{220\}_{\mathrm{S}}$ also occurs in case of epitaxial growth of a perovskite manganite film on a $\mathrm{Z}$ substrate [37].

Interfaces between $\mathbf{A}$ and $\mathbf{S}$ show a near parallelism of several dense planes of both phases, the deviation being less than $3^{\circ}$. Facets are strictly parallel to dense planes; the interface passes through the near coincidence sites and the steps accommodate the misfits. For all other interfaces, faceting occurs preferentially along dense A planes.

For polar interface planes, the interface is centred on oxygen columns. All these features probably induce low energy $\mathrm{A} / \mathrm{S}$ interfaces.

The presence of cohesive interfaces with low energy is a favourable factor to the good flexural strength behaviour of ternary A-Y-Z eutectic and eutectics containing a perovskite phase.

\section{Conclusion}

The variation in orientation relationships according to the number of phases involved in the growth of eutectic oxides reflects the predominant role of interfacial energy on the OR selection.

Alumina-zirconia interfaces are semicoherent, strongly faceted, and are parallel to dense planes of both phases or parallel to dense planes of alumina. The OR is the same in binary and ternary eutectics. Zirconia modifies the OR between $\mathrm{Y}_{3} \mathrm{Al}_{5} \mathrm{O}_{12}$ and alumina found in the binary eutectic, and geometrical arguments show that the $\mathrm{Y}_{3} \mathrm{Al}_{15} \mathrm{O}_{12}$ and zirconia have a preferred orientation in ternary. Interfaces between $\mathrm{Y}_{3} \mathrm{Al}_{5} \mathrm{O}_{12}$ and alumina are parallel to dense planes of one or two phases, the OR between $\mathrm{Y}_{3} \mathrm{Al}_{15} \mathrm{O}_{12}$ and alumina being however most often deviated from the perfect OR

Alumina-perovskite interfaces are semicoherent or incoherent, and are parallel to dense planes of both phases or parallel to dense planes of alumina, as found for alumina zirconia interfaces. Interfaces pass through the near coincidence sites. The OR of zirconia with alumina is different from this $\mathrm{OR}$ in the eutectic with $\mathrm{Y}_{3} \mathrm{Al}_{15 \mathrm{O}_{12}}$ phase, probably in order to get low energy interfaces between zirconia and perovskite.

For both systems, these results show that variations in OR are in favour of a simultaneous growth of the three phases at the beginning of solidification. 


\section{Acknowledgments}

The authors thank the Region Ile-de-France for convention SESAME 2008 E1845, which supports the JEOL ARM 200F electron microscope installed at MPQ (UMR7162), and Guillaume Wang for his kind assistance on the microscope. This work was supported by the Agence Nationale pour la Recherche through the CINATRA project ANR-12-RNMP-0008, the METSA network and the European 7th framework program "ESTEEM2". Michael Walls from the Laboratoire de Physique des Solides of the University Paris XI in Orsay (France) is gratefully acknowledged for his reading of the manuscript.

\section{The authors declare that they have no conflict of interest}

\section{References}

[1] Waku Y, Nakagawa N, Wakamoto T, et al (1997) A ductile ceramic eutectic composite with high strength at $1873 \mathrm{~K}$. Nature 389:49-52.

[2] Nakagawa N, Waku Y, Wakamoto T, et al (2000) High temperature properties and thermal stability of a unidirectionally solidified $\mathrm{Al}_{2} \mathrm{O}_{3} / \mathrm{Er}_{3} \mathrm{Al}_{5} \mathrm{O}_{12}$ eutectic composites. J. Jpn. Inst. Met. 64: 101-107

[3] Yasuda H., Ohnaka I., Mizutani Y. et al (2005) Three dimensional observation of the entangled eutectic structure in the $\mathrm{Al}_{2} \mathrm{O}_{3} / \mathrm{YAG}$ system. J Eur Ceram Soc 25:1397-1403

[4] Ochiai S, Ueda T, Sato K, et al (2001) Deformation and fracture behavior of an $\mathrm{Al}_{2} \mathrm{O}_{3} / \mathrm{YAG}$ composite from room temperature to $2023 \mathrm{~K}$. Compos Sci Technol 61:21172128 .

[5] Nakagawa N, Ohtsubo H, Mitani A, et al (2005) High temperature strength and thermal stability for melt growth composite. J Eur Ceram Soc 25:1251-1257.

[6] Pastor JY, LLorca J, Salazar A, et al (2005) Mechanical Properties of Melt-Grown Alumina-Yttrium Aluminum Garnet Eutectics up to 1900 K. J Am Ceram Soc 88:1488-1495.

[7] Hirano K (2005) Application of eutectic composites to gas turbine system and fundamental fracture properties up to $1700^{\circ} \mathrm{C}$. J Eur Ceram Soc 25:1191-1199.

[8] Llorca J, Orera V.M. (2006) Directionally solidified eutectic ceramic oxides. Prog. Mat. Sci. 51 (6) 711-809 
[9] Waku Y, Sakata S, Mitani A, et al (2002) Temperature dependence of flexural strength and microstructure of $\mathrm{Al}_{2} \mathrm{O}_{3} / \mathrm{Y}_{3} \mathrm{Al}_{5} \mathrm{O}_{12} / \mathrm{ZrO}_{2}$ ternary melt growth composites. J Mater Sci $37: 2975-2982$.

[10] Larrea A., Orera V.M., Merino R.I., Pena J.L. (2005) Microstructure and mechanical properties of $\mathrm{Al}_{2} \mathrm{O}_{3} / \mathrm{YSZ}$ and $\mathrm{Al}_{2} \mathrm{O}_{3} / \mathrm{YAG}$ directionally solidified eutectic plates J. Eur. Ceram. Soc. $25: 1419-1429$

[11] Calderon-Moreno JM, Yoshimura $\mathrm{M}$ (2005) $\mathrm{Al}_{2} \mathrm{O}_{3} / \mathrm{Y}_{3} \mathrm{Al}_{12} \mathrm{O}_{12}(\mathrm{YAG}) / \mathrm{ZrO}_{2}$ ternary composite rapidly solidified from the eutectic melt. J Eur Ceram Soc 25:1365-1368.

[12] Pena J.L. , Larsson M., Merino R.I.,et al. (2006) Processing, microstructure and mechanical properties of directionally-solidified $\mathrm{Al}_{2} \mathrm{O}_{3}-\mathrm{Y}_{3} \mathrm{Al} \mathrm{O}_{12}-\mathrm{ZrO}_{2}$ ternary eutectics $\mathrm{J}$. Eur. Ceram. Soc. $26: 3113-3121$

[13] Waku Y, Sakata S, Mitani A, et al (2005) Microstructure and high-temperature strength of $\mathrm{Al}_{2} \mathrm{O}_{3} / \mathrm{Er}_{3} \mathrm{Al}_{512} \mathrm{O}_{12} / \mathrm{ZrO}_{2}$ ternary melt growth composite. J Mater Sci 40:711-717.

[14] Mazerolles L, Perriere L, Lartigue-Korinek S, et al (2008) Microstructures, crystallography of interfaces, and creep behavior of melt-growth composites. J Eur Ceram Soc 28:2301-2308.

[15] Mazerolles L, Perriere L, Lartigue-Korinek S, Parlier M (2011) Creep behavior and related structural defects in $\mathrm{Al}_{2} \mathrm{O}_{3}-\mathrm{Ln}_{2} \mathrm{O}_{3}\left(\mathrm{ZrO}_{2}\right)$ directionally solidified eutectics $(\mathrm{Ln}=\mathrm{Gd}, \mathrm{Er}$, Y). J Eur Ceram Soc 31:1219-1225.

[16] Waku Y (1998) A new ceramic eutectic composite with high strength at $1873 \mathrm{~K}$. Adv Mater 10:615-617.

[17] Mazerolles L, Trichet MF, Piquet N, Parlier M (2006) Microstructures and Interfaces in Melt-Growth $\mathrm{Al}_{2} \mathrm{O}_{3}-\mathrm{Ln}_{2} \mathrm{O}_{3}$ Based Eutectic Composites. In: 11th Int. Ceram. Congr. Trans Tech Publications, pp 1377-1384

[18] Waku Y, Fujiwara N (2014) Ceramic composite material, JP 2014-169191 A.

[19] Londaitzbéhère L, Lartigue-Korinek S, Mazerolles L (2017) Microstructure, interfaces and creep behaviour of $\mathrm{Al}_{2} \mathrm{O}_{3}-\mathrm{Sm}_{2} \mathrm{O}_{3}\left(\mathrm{ZrO}_{2}\right)$ eutectic ceramic composites. J Mater Sci 52 : $5489-5502$.

[20] Ma YH, Ouyang JH, Wang ZG, Henniche A, Wang YH, Wang YJ, Liu ZG (2019) Insights into intragranular precipitation and strengthening effect in $\mathrm{Al}_{2} \mathrm{O}_{3} / \mathrm{SmAlO}_{3}$ ceramic with eutectic composition. Mater Sci Eng A754: 382-389.

[21] Perriere L, Valle R, Carrere N, et al (2011) Crack propagation and stress distribution in binary and ternary directionally solidified eutectic ceramics. J Eur Ceram Soc 31:1199-1210. 
[22] Benamara O, Cherif M, Duffar T Lebbou K (2015) Microstructure and crystallography of $\mathrm{Al}_{2} \mathrm{O}_{3}-\mathrm{Y}_{3} \mathrm{Al}_{5} \mathrm{O}_{12}-\mathrm{ZrO}_{2}$ ternary eutectic oxide grown by the micropulling down technique $\mathrm{J}$ Cryst Growth 429: 27-34.

[23] MacTempas: website http://www.totalresolution.com

[24] Londaitzbéhère L, PHD Dissertation, Thiais 2016

[25] Mazerolles L, Michel D, Hÿtch MJ (2005) Microstructures and interfaces in directionally solidified oxide-oxide eutectics. J Eur Ceram Soc 25: 1389-1395.

[26] Cain MG, Lange FF (1994) Heteroepitaxy of cubic zirconia on basal and prismatic planes of sapphire. J Mater Res 9 : 674-687

[27] Frazer CS, Dickey EC, Sayir A (2001) Crystallographic texture and orientation variants in $\mathrm{Al}_{2} \mathrm{O}_{3}-\mathrm{Y}_{3} \mathrm{Al}_{5} \mathrm{O}_{12}$ directionally solidified eutectic crystals. J Cryst Growth 233:187-195.

[28] Waku Y, Nakagawa N, Ohtsubo H, Mitani A, Shimizu K (2001) Fracture and deformation behaviour of melt growth composites at very high temperatures. J Mater Sci $36: 1585-1594$.

[29] Waku Y, Sakata S, Mitani A, Shimizu K, Hasebe M (2002) Temperature dependence of flexural strength and microstructure of $\mathrm{Al}_{2} \mathrm{O}_{3}-\mathrm{Y}_{3} \mathrm{Al}_{5} \mathrm{O}_{12}-\mathrm{ZrO}_{2}$ ternary melt growth composites. J Mater Sci 37: 2975-2982.

[30] Hay R and Matson L (1991) Alumina Yttrium-Aluminum-Garnet Crystallographic Orientation Relationships and Interphase Boundaries - Observations and Interpretation by Geometric Criteria. Acta Metal Mater 39: 1981-1994.

[31] Wang X, Zhong YJ, Wang D, Xian QG, Wang JY, Lou LH, Zhang J (2017) Effect of interfacial energy on microstructure of a directionally solidified $\mathrm{Al}_{2} \mathrm{O}_{3}-\mathrm{YAG}$ eutectic ceramic. Scr Mater 135 :46-49.

[32] Wang X, Zhong YJ, Sun Q, Li Y, Zhang W, Qi D, Wang D, Jiang B (2018) Crystallography and interfacial structure in a directionally solidified $\mathrm{Al}_{2} \mathrm{O}_{3}-\mathrm{Y}_{3} \mathrm{Al}_{5} \mathrm{O}_{12}-\mathrm{ZrO}_{2}$ eutectic crystal. Scr Mater 145: 23-27

[33] Deng H, Dickey EC, Paderno Y, Paderno V, Filippov V (2007) Interface Crystallography and structure in $\mathrm{LaB}_{6}-\mathrm{ZrB}_{2}$ directionally solidified eutectics. J of Am Ceram Soc 90:26032609.

[34] Sieber H, Hesse D, Senz S, Heydenreich J, Pan X (1996) TEM Investigations of Spinelforming Solid State Reactions: Mechanism, film orientation, and interface structure during $\mathrm{MgAl}_{2} \mathrm{O}_{4}$ formation on $\mathrm{MgO}(001)$ and $\mathrm{Al}_{2} \mathrm{O}_{3}(1-1.2)$ single crystal substrates. $\mathrm{Z}$ Anorg Allg Chem 622:1658-1666 
[35] Waku Y, Sakata S, Mitani A, Shimizu K (2001) A novel oxide composite reinforced with a ductile phase for very high temperature structural materials. Mater Res Innov 5: 94100.

[36] Waku Y, Sakata S, Mitani A, Shimzu K, Ohtsuka A, Hasebe M (2005) Microstructure and high-temperature strength of $\mathrm{Al}_{2} \mathrm{O}_{3}-\mathrm{Er}_{3} \mathrm{Al}_{5} \mathrm{O}_{12}-\mathrm{ZrO}_{2}$ ternary melt growth composite. $\mathrm{J}$ Mater Sci 40: 711-717.

[37] Gorbenko OY, Graboy IE, Kaul AR (2000) HREM and XRD characterization of epitaxial perovskite manganites. J Magn Magn Mater 211 : 97-104

\section{Captions}

Fig. 1 Bright field image showing the microstructure of the ternary eutectic $\mathrm{Al}_{2} \mathrm{O}_{3}-\mathrm{Y}_{3} \mathrm{Al} \mathrm{O}_{12^{-}}$ $\mathrm{ZrO}_{2}$

Fig. 2 Bright field image showing rounded interfaces between alumina and zirconia.

Fig. 3 Parallel or nearly parallel dense planes in alumina and zirconia lattices sharing a common $[10 \overline{1} 0]_{A} / /[001]_{Z}$ projection axis.

Fig. 4(a) HRTEM image of an interface parallel to a basal plane in alumina and a (020) plane in zirconia (image Topcon).

Fig. 4(b) Enlarged view of Fig. 4(a): Circuit around a step.

Fig. 4(c) Circuit of Fig. 4(b) reported in a constrained dichromatic pattern (blue: zirconia, orange: Alumina).

Fig. 5(a) HRTEM image showing an interface between alumina and zirconia faceted along dense planes of both phases. The misfit dislocations that accommodate both misfits are localized at the left end of basal facets (blue and red dots).

Fig. 5(b) Enlarged view of a facet parallel to the basal plane in alumina with superimposition of simulations and 2D structural model.

Fig. 6(a) HRTEM image showing an interface between alumina and zirconia with large facets parallel to $(\overline{1} 2 \overline{1} 0)_{A} / /(200)_{Z}$.

Fig. 6(b) Enlarged view of a facet with superimposition of a 2D structural model (Blue:

Oxygen, green: Zirconia, Red: Aluminium) 
Fig. 7 HRTEM image showing an interface between alumina and zirconia with large facets parallel to $(\overline{1} 2 \overline{1} 0)_{A} / /(200)_{Z}$ in a binary eutectic. The projection axis is [0001] in alumina. The white arrows indicate the steps. The small templates (blue and orange dots) reveal the incoherent character of the interface.

Fig. 8 HRTEM image showing an interface between alumina and zirconia with facets parallel to $(\overline{1} 2 \overline{1} 3)_{A}$. The inclined facets are parallel to the basal plane in alumina and to a (020) plane in zirconia.

Fig. 9 HRTEM image of a faceted interface in a ternary eutectic $\mathrm{Al}_{2} \mathrm{O}_{3}-\mathrm{Y}_{3} \mathrm{Al}_{5} \mathrm{O}_{12}-\mathrm{ZrO}_{2}$. (projection axis $\left.[10 \overline{1} 0]_{A} / /[001]_{Y A G}\right)$. Large facets are parallel to the $(400)_{Y A G}$ plane. The small facets are parallel to the basal alumina plane.

Fig. 10 Dichromatic complex showing parallel dense planes between YAG and zirconia phases (Blue: Aluminium in YAG, orange: Zirconia lattice).

Fig. 11 HRTEM image of an interface between YAG and zirconia.

Fig. 12 HRTEM image of an interface between YAG and zirconia showing nanofacets along the $(040)_{\text {YAG }}$ plane.

Fig. 13 HRTEM image of an interface between YAG and zirconia. The interface is parallel to a (240) plane in zirconia.

Fig. 14 Bright field image showing the microstructure of the ternary eutectic $\mathrm{Al}_{2} \mathrm{O}_{3}-\mathrm{SmAlO}_{3}$ $\mathrm{ZrO}_{2}$. The white arrow indicates a basal twin in the alumina phase.

Fig. 15 Dichromatic patterns showing parallel or nearly parallel dense planes in alumina and perovskite (subscript SAP) (a) $[\overline{2} 110]_{A} / /[100]_{S A P}$ zone axis (b) $[2 \overline{1} \overline{1} 0]_{A} / /[100]_{S A P}$ zone axis.

Fig. 16 (a) HRTEM images of a stepped interface with facets parallel to $(01 \overline{1} 2)_{A}$ and $(020)_{S A P}$ planes $\left([\overline{2} 110]_{A} / /[100]_{S A P}\right.$ zone axis $)$.

Fig. 16(b) Dichromatic pattern between alumina and SAP: The mean interface plane shares near coincidence sites.

Fig. 17 (a) HRTEM images of a stepped interface with facets parallel to the basal plane in alumina and the $(01 \overline{1})_{S A P}$ plane $\left([2 \overline{1} \overline{1} 0]_{A} / /[100]_{S A P}\right.$ zone axis). 
Fig. 17(b) Schematic model of the interface (lattice sites in blue (SAP) and orange (alumina)).

Fig. 18 HRTEM image of a faceted interface showing a large facet parallel to a $(01 \overline{1} 8)_{A}$ plane in alumina.

Fig. 19 Dichromatic pattern between SAP and zirconia (projection along [011] Z axis). 